Revista Vernáculo, $n .26,2^{\circ}$ sem./2010

\title{
PAI NOSSO DOS MÁRTIRES: REPENSANDO O DECLÍNIO DA TEOLOGIA DA LIBERTAÇÃO
}

\author{
João Pedro da Luz Neto
}

Resumo: O presente trabalho, através de uma perspectiva da história cultural, procura compreender melhor os motivos do declínio da teologia da libertação.

Palavras-chave: Teologia da Libertação; História das Religiões; Igreja Católica; América Latina.

* Graduando em História da Universidade Federal do Paraná. 


\section{PAI NOSSO DOS MÁRTIRES: REPENSANDO O DECLÍNIO DA TEOLOGIA DA LIBERTAÇÃO}

João Pedro da Luz Neto

Medellín e Puebla constitui hoje uma fórmula tanto comum quanto equívoca. Equívoca, no sentido justo da palavra: não podemos citar os dois documentos como pertencentes a uma mesma linha teológica. ${ }^{1}$

\section{I}

A dificuldade do estudo historiográfico da Teologia da Libertação ${ }^{2}$ é, sobretudo, a ausência de pesquisa sobre o tema: muitas vezes encontramos os próprios militantes reconstituindo a memória da Teologia; estes homens, mesmo que tenham o interesse em fazer uma análise imparcial do assunto, jamais o conseguirão: se para o historiador o exercício da neutralidade já é difícil (senão impossível),

\footnotetext{
${ }^{1}$ SEGUNDO, Juan Luis. "Introdução Para não se perder”. Ciberteologia - Revista de Teologia \& Cultura - Ano II, n. 12, pp. 34-44.

${ }^{2}$ A partir de agora, vou me referir a ela como Teologia.
} 
como acreditar em alguém tão íntimo do objeto de estudo, ou melhor, que é o próprio objeto de estudo?

Da mesma forma, as dificuldades se impõem ao historiador: em muitas vezes, a tese do objeto de estudo mescla-se com a tese do estudante; assim, já não se produz um trabalho plenamente analítico, mas bastante engajado no que diz respeito às principais questões da Igreja contemporânea. Não podemos culpar ninguém; a proximidade que temos com o tema, com o contexto, com a instituição eclesiástica, são filtros para a compreensão histórica do tema. Desta forma, não me sinto habilitado em dizer que somente a partir de agora estudos históricos serão feitos, mas apenas em situar outros aspectos de sua trajetória que, a meu ver, contribuirão para uma visão mais ampla desta.

\section{II}

Muitas vezes os trabalhos já referidos percebem o declínio do movimento como fruto de uma forte pressão do Vaticano, exaltada, por vezes, na figura do Papa João Paulo II, e do então cardeal Joseph Ratzinger, prefeito da Sagrada Congregação para a Doutrina da Fé, os quais se opuseram a alguns dos aspectos centrais da Teologia.

Ao tomar essa posição, tem-se uma visão um pouco simplista da História, como uma mera relação de causa-efeito em que as causas são únicas e diretas. Da mesma forma com que Janice Theodoro questiona a ausência dos índios na historiografia da América 
Colonial $^{3}$, também há de se indagar aqui onde está o povo, objetivo da Teologia: há que se questionar a eficácia do Vaticano, se os documentos pontifícios eram lidos pela população... Talvez existam outros motivos que, somados à crítica e pressão do Vaticano aos extremos da Teologia, contribuam para seu declínio.

\section{III}

Para Edvania Silva, a Renovação Carismática Católica (RCC) disputa o mesmo público da Teologia da Libertação ${ }^{4}$; no entanto, o primeiro movimento é mais midiático e individualista, até mesmo por conta de suas origens, no centro do capitalismo ${ }^{5}$, e bem mais conservador, ao contrário da Teologia. Edvania Silva ainda mostra que a ação dentro da RCC é vista como oração, enquanto na Teologia, como luta ${ }^{6}$. Claudete Soares nota a preferência dos populares em questão para a $\mathrm{RCC}^{7}$. Não entraremos em detalhes,

\footnotetext{
3 THEODORO, Janice. América Barroca. São Paulo: Edusp; Rio de Janeiro: Nova Fronteira, 1992.

${ }^{4}$ SILVA, Edvania Gomes da. Os (des)encontros da fé: análise interdiscursiva de dois movimentos da Igreja Católica. Tese. Universidade Estadual de Campinas, 2006, pp. 53-55.

5 CARRANZA DAVILA, Brenda Maribel. Renovação Carismática Católica: origens, mudanças e tendências. Dissertação. Universidade Estadual de Campinas, 1998, pp. 21-23.

${ }^{6}$ SILVA, op. cit., p. 271.

${ }^{7}$ CARRANZA DAVILA, op. cit., p. 132.
} 
uma vez que o objetivo deste trabalho é analisar a própria Teologia, e não suas relações com outros grupos; no entanto, certamente a RCC contribuiu para o declínio da Teologia.

\section{IV}

Para Westphal ${ }^{8}$, houve falhas na comunicação entre os Teólogos e as Comunidades Eclesiais de Base ${ }^{9}$ É justamente sobre essa falha na comunicação que iremos tratar; não na busca em História Oral em contraposição com o discurso oficial da Teologia, como fez Westphal, mas numa análise sobre o conteúdo e a forma das discussões entre os teólogos e apresentações das discussões para o público em geral. Evidentemente, a discussão teológica é bem mais complexa (e profunda) que a apresentação do tema aos leigos; agora, em que medida essa apresentação é uma síntese da Teologia?

8 WESTPHAL, Ezequiel. Nos bastidores da igreja: reflexos do declínio da influência da teologia da libertação nas pastorais da arquidiocese de Curitiba (1981-1992). Dissertação. Universidade Estadual de Ponta Grossa, 2008, p. 163.

${ }^{9}$ Discorrerei sobre elas no $\mathrm{n}^{\circ}$ VII. 


\section{V}

A Encíclica Populorum Progresio e o Concílio Vaticano II foram trampolins para a gênese do pensamento da Teologia ${ }^{10}$, e o termo Teologia da Libertação foi cunhado, em primeira instância, por Gustavo Gutiérrez, padre peruano ${ }^{11}$. Suas origens não são tão latino-americanas assim: Edvania Silva comenta que teólogos alemães, e principalmente franceses, auxiliarão na concepção da análise $^{12}$. No entanto, podemos situar a Teologia como um movimento teológico nascido na América Latina e para a América Latina. Sua opção é preferencial aos pobres, em oposição às elites dominantes ${ }^{13}$. O termo pobres pode ser ampliado para excluídos: a Teologia buscará enfatizar as mulheres ${ }^{14}$, crianças, os jovens,

10 BELIEVE Religious Information web-site (http://mbsoft.com/believe/txn/liberati.htm), Apud Berryman, Phillip, Liberation Theology Philadelphia: Temple University Press, 1987; Sigmund, P.E., Liberation Theology at the Crossroads. New York: Oxford University Press, 1990.

${ }^{11}$ SILVA, op. cit., p. 60.

${ }^{12}$ Idem, pp. 60-61.

${ }^{13}$ SOARES, Claudete Gomes. Teologia da Libertação no Brasil: Aspectos de uma crítica político-teológica à sociedade capitalista. Dissertação. Universidade Estadual de Campinas, 2000, p.37.

14 III CONFERÊNCIA GERAL DO EPISCOPADO LATINO-AMERICANO. Puebla: a evangelização no presente e no futuro da América Latina. Petrópolis: Vozes, 1980. nº 834 a 841. 
indígenas, afro-americanos, camponeses, operários, desempregados, subempregados, marginalizados e idosos ${ }^{15}$.

Em todas as periodizações lidas pelo autor, a divisão é mais ou menos a mesma; apresento aqui a mesma divisão de Westphal, por ser a mais clara ${ }^{16}$. Como princípio, marcam-se os anos de 1959 a 1968, com a preparação da Teologia, num período de uma forte teologia progressista que, gradativamente, começa a ser questionada. É entre 1968 e 1972 que a base da Teologia será discutida e formulada; com o agravo das opressões ditatoriais (particularmente no Brasil), começam a perseguir esses teólogos, já taxados de marxistas radicais. Em 1976 surge a quarta fase, de um crescimento significativo; a partir do final dos anos 80 , começa então o seu declínio.

\section{VI}

Os documentos aqui analisado, cuja data de produção é sabida pelo autor, são justamente desse momento do apogeu da Teologia: a conferência de Puebla (1979) e a explicação de Frei Betto sobre as Comunidades Eclesiais de Base (1981); analisar-se-á, ainda, músicas da Teologia, de vários autores, e um Credo, de Frei Betto.

\footnotetext{
${ }^{15}$ Idem, no 31 a 39.

${ }^{16}$ WESTPHAL, op. cit., pp. 57-60.
} 


\section{VII}

As Comunidades Eclesiais de Base (CEBs) constituem grupos de pessoas, geralmente de classe baixa, que moram na mesma comunidade e partilham de uma mesma fé $\mathrm{e}^{17}$, as quais se encontram para refletir e transformar a realidade à luz da Palavra de Deus e das motivações religiosas ${ }^{18}$. Começavam também a reivindicar pequenas melhorias nos bairros, mas, ao mesmo tempo, iniciavam uma caminhada para tomar consciência da situação social e política. ${ }^{19}$

Para a Congregação Nacional dos Bispos do Brasil (CNBB), a opção pelos pobres, característica das CEBs têm uma conotação evangélica profunda, baseada no próprio Evangelho ${ }^{20}$, e nasceram com o intuito de renovar a Igreja, auxiliando ainda mais no trabalho pastoral e evangelizador. ${ }^{21} \mathrm{Da}$ mesma forma posiciona-se a

${ }^{17}$ BETTO, Frei. O que é Comunidade Eclesial de Base. São Paulo: Brasiliense, 1981, pp. 17-20.

${ }^{18}$ Idem, pp. 29-32; III CONFERÊNCIA..., op. cit., no 643.

19 Pontifício Instituto Missões Exteriores; disponível em: http://www.pime.org.br/mundoemissao/igrejacebs.htm.

${ }^{20} 7^{\text {a }}$ REUNIÃO ORDINARIADO CONSELHO PERMANENTE. As comunidades eclesiais de base na igreja do Brasil. Brasília, 23 a 26 de novembro de 1982. Disponível em: http://www.cnbb.org.br/documento_geral/LIVRO\%2025AS\%20COMUNIDADES\%20BRASIL.pdf. №. 44

${ }^{21}$ Idem, n ${ }^{\circ} 03$. 
Conferência de Puebla, ao afirmar que "As CEBs são expressão do amor preferencial da Igreja pelo povo simples....". ${ }^{22}$

Até o momento, não há o porquê de se estabelecer conflitos; todos os teólogos do movimento concordam na preferência pelos pobres $^{23}$; a desunião da Teologia surge quanto ao processo evangelizador dessas comunidades.

\section{VIII}

Como já foi comentado, a CNBB afirma a posição evangelizadora das CEB's ${ }^{24}$; igualmente a Conferência de Puebla ${ }^{25}$; tal posição é coerente com a doutrina católica, em que todos são chamados a evangelizar em seu cotidiano ${ }^{26}$.

Enquanto isso, para Frei Betto, a missão do homem comum é lutar (referência); da mesma forma muitos outros discursos tomam tal atitude, como indica Edvania Silva ${ }^{27}$. Segundo a referida autora, a oposição entre os semas ação e alienação constituem a base do discurso da Teologia, que, quando aplicada ao cristianismo, torna-se luta. Edvania prossegue:

\footnotetext{
${ }^{22}$ III CONFERÊNCIA..., op. cit., $\mathrm{n}^{\circ} 643$.

${ }^{23} \mathrm{Cf} . \mathrm{n}^{\circ} \mathrm{V}$.

${ }^{24}$ Ver nota 21.

${ }^{25}$ III CONFERÊNCIA..., op. cit., no 1147.

${ }^{26}$ CATECISMO DA IGREJA CATÓLICA. São Paulo: Edições Loyola, 1999, nº 849 e 905.

${ }^{27}$ SILVA, op. cit., p. 269.
} 
O Jesus Cristo dos teólogos da libertação é um homem de ação. Alguém que veio do povo (dimensão humana do Cristo) e, por isso, entende as dores e o sofrimento dos marginalizados. É um Cristo que promove a /Libertação/ e que se opõe a qualquer tipo de /Dominação/, principalmente, à dominação dos poderosos sobre os menos favorecidos. Trata-se, portanto, da sobreposição do /Humano/ em relação ao /Divino/ e, conseqüentemente, da /Ação/ em oposição à /Contemplação. ${ }^{28}$

Como se vê, ainda que a ação nos documentos da elite hierárquica da igreja latino-americana seja relacionada com evangelização, não é o que se encontra no livro de Frei Betto, publicado dois anos depois de Puebla. ${ }^{29}$

\section{IX}

Igualmente, as músicas da Teologia pouco se preocupam com o ideal evangelizador: o Irmão Vaz Castilho coloca como refrão de sua música Pão da Igualdade:

É Jesus este pão de igualdade, viemos pra comungar / Com a luta sofrida do povo que quer ter voz, ter vez, lugar /

\footnotetext{
${ }^{28}$ Idem.

${ }^{29}$ BETTO, op. cit..
} 
Comungar é tornar-se um perigo, viemos pra incomodar/ Com a fé e união, nossos passos um dia vão chegar. ${ }^{30}$

Como se vê, a revolta, insatisfação, é um tema bastante presente, na formação de um discurso em que é fundamental o agir. $\mathrm{Na}$ concepção da Teologia, as CEBs devem sempre agir, depois de devidamente estudado o problema ${ }^{31}$. Percebemos, pois, uma divergência entre a função estabelecida em Puebla ${ }^{32}$ e a transmissão para os pobres dos objetivos da Teologia.

\section{$\mathbf{X}$}

Outro dado interessante é a união; ela está num plano micro, como o da CEB, mas também macro, ressaltando a unidade da América Latina, em torno de seus problemas, e sua ânsia una por um mundo melhor. Padre Zezinho destaca:

Toda a América Latina está cantando um canto de libertação /

Canta por fraternidade, por mais liberdade, por mais união /

30 CASTILHO, Vaz. Pão da Igualdade. Disponível em: http://www.latinoamericano.jor.br/musica_igreja_progressista.html.

${ }^{31}$ BETTO, op. cit., pp. 21-23.

${ }^{32}$ Cf. $n^{\circ}$ VIII. 
Toda a América Latina está cantando um canto de libertação.33

Não é o único; Zé Vicente canta:

Pelos caminhos da América há tanta dor, / Tanto pranto, nuvens, mistérios, / Encantos que envolvem nosso caminhar. / Há cruzes beirando a estrada, / Pedras manchadas de sangue, / Apontando como setas, / Que a liberdade é pra lá. ${ }^{34}$

Como se percebe, essa união, que se faz em torno de uma mesma exploração, difere um pouco da união pela fé, característica das CEB's ${ }^{35}$ :

A comunidade eclesial de base (...) realiza a Palavra de Deus
na vida, através da solidariedade e compromisso com o
mandamento novo do Senhor e torna presente e atuante a
missão eclesial (...). ${ }^{36}$

Mais um exemplo de falha na comunicação entre as elites da Teologia e os pequenos da Teologia.

33 ZEZINHO, Padre. Toda a América Latina. Disponível em: http://vagalume.uol.com.br/padre-zezinho/toda-a-america-latina.html. 34 VICENTE, Zé. Pelos Caminhos da América. Disponível em: http://www.latinoamericano.jor.br/musica_igreja_progressista.html.

${ }^{35} \mathrm{E}$, além do trecho citado, convém rever o ${ }^{\circ}$ VII.

${ }^{36}$ III CONFERÊNCIA..., op. cit., no 641. 


\section{XI}

Frei Betto esclarece ao público em geral como se dá a fé dele:

Creio no Deus desaprisionado do Vaticano e de todas as religiões existentes e por existir. Deus que precede todos os batismos, pré-existe aos sacramentos e desborda de todas as doutrinas religiosas. (...) Creio no Deus que não tem religião (...). Creio no Deus que se faz sacramento em tudo que aproxima, atrai, enlaça, abraça e une - o amor. ${ }^{37}$

Enquanto isso, um documento produzido dois anos antes, e que deveria conduzir os rumos da Teologia, afirma: "[a piedade popular] (...) apresenta também aspectos negativos: (...) sincretismo religioso..." ${ }^{38}$; e ainda:

A Igreja é, por sua vez, sacramento de Cristo (cf. Lumen Gentium, 1) para comunicar aos homens a vida nova. Os sete sacramentos da Igreja concretizam e atualizam esta realidade sacramental para as diversas situações da vida. ${ }^{39}$

37 BETTO, Frei. Creio. Disponível em: http://www.comunidadeespiritual.com/profile.php?sub_section=view_blogerid=394\&sub_id=7688.

${ }^{38}$ III CONFERÊNCIA..., op. cit., $\mathrm{n}^{\circ} 914$.

${ }^{39}$ Idem, n ${ }^{\circ} 922$. 


\section{XII}

Ao longo dos pontos VIII, IX, X e XI, procurei analisar dentro das fontes primárias, algumas feitas para as elites da Teologia, que são os próprios idealizadores e mantenedores dela, e outras concebidas dessas elites para os pobres, com o intuito de divulgar a Teologia. Essas comparações foram gradativamente construídas ao longo do processo de pesquisa, e apenas apresentadas nesses pontos. Optou-se aqui por um menor número de comparações para permitir a exibição das próprias fontes, na tentativa de fornecer ao leitor o próprio material analisado pelo autor.

Tais comparações nos levam a crer que havia, de fato, uma falha na comunicação entre os teólogos e a população, aqui sempre vista na concepção de CEB. Tomando essa perspectiva, tem-se que a compreensão popular da Teologia não era a proposta pelas elites. Como se percebe a Teologia da Libertação não entrou em declínio pela simples crítica do Vaticano. Ela não conseguiu atingir os populares que tanto queria ${ }^{40}$. E é aqui que tomamos a citação de Juan Luis Segundo, logo no início deste artigo: a Teologia não conseguiu, nunca, ser una, no sentido mais profundo do termo.

${ }^{40}$ WESTPHAL, op. cit., p. 164. 


\section{Bibliografia}

$7^{\text {a }}$ REUNIÃO ORDINARIADO CONSELHO PERMANENTE. As comunidades eclesiais de base na igreja do Brasil. Brasília, 23 a 26 de novembro de 1982. Disponível em: http://www.cnbb.org.br/documento_geral/LIVRO\%2025AS\%20COMUNIDADES\%20BRASIL.pdf. Acessado em $23 / 02 / 11$

BETTO, Frei. O que é Comunidade Eclesial de Base. São Paulo: Brasiliense, 1981.

CARRANZA DAVILA, Brenda Maribel. Renovação Carismática Católica: origens, mudanças e tendências. Dissertação. Universidade Estadual de Campinas, 1998, pp. 7-67.

III CONFERÊNCIA GERAL DO EPISCOPADO LATINOAMERICANO. Puebla: a evangelização no presente e no futuro da América Latina. Petrópolis: Vozes, 1980.

SEGUNDO, Juan Luis. Introdução "Para não se perder". Ciberteologia - Revista de Teologia \& Cultura. Disponível em: $\quad$ http://www.paulinas.org.br/ciberteologia/wpcontent/uploads/2009/06/05introducaoparanaoseperder.pdf, acesso em 26/11/09.

SILVA, Edvania Gomes da. Os (des)encontros da fé: análise interdiscursiva de dois movimentos da Igreja Católica. Tese. Universidade Estadual de Campinas, 2006. 
SOARES, Claudete Gomes. Teologia da Libertação no Brasil: Aspectos de uma crítica político-teológica à sociedade capitalista. Dissertação. Universidade Estadual de Campinas, 2000 .

WESTPHAL, Ezequiel. Nos bastidores da igreja: reflexos do declínio da influência da teologia da libertação nas pastorais da arquidiocese de Curitiba (1981-1992). Dissertação. Universidade Estadual de Ponta Grossa, 2008. 